\title{
Making Water Count: A Systematic Review To Inform The Design Of A Household Water-Saving Community Engagement Program
}

\author{
Desi Adhariani \\ Department of Accounting \\ Faculty of Economics and Business, Universitas Indonesia \\ Depok, Indonesia \\ desi.adhariani@ui.ac.id
}

\begin{abstract}
This paper presents a systematic literature review of water saving in household consumption to inform the design of community engagement programs. Drawing from theoretical perspectives and previous studies on determinants of water saving, this study proposes a design of a community engagement program to empower the community in tackling the issue of water scarcity by considering several factors. The program also inserts the knowledge of calculative behavior applied in the accounting area to support the water efficiency program in household consumption. The role of accounting demonstrates that measurement is important for understanding the patterns of water usage as part of the accountability system to gradually change behavior.
\end{abstract}

Keywords-water saving, water counting, community engagement

\section{INTRODUCTION}

One of the largest environmental challenges faced by the world today is the scarcity of water: current water use already exceeds renewable supply. The water crisis has brought about a threat to the sustainable development of human society [1] and has become a sizeable global risk because of its potentially devastating impact [2]. Many factors contribute to the rising global demand for water, such as the increasing world population, changing consumption patterns, improving living standards, and expansion of irrigation for agriculture [3].

The problem is faced by many countries, including Indonesia. Analysis performed by the National Institute of Aeronautics and Space found that as of July 2017, based on the level of vegetation drought, in general, most of Indonesia is in normal to dry condition. Most areas of Sumatra Island are in normal condition, except in some areas of Aceh, North Sumatra, parts of South Sumatra, and some of Lampung that appear dry. On the island of Borneo, however, almost half of the territory is in relatively dry conditions with Central Kalimantan, East Kalimantan, North Kalimantan, and South Kalimantan being the driest. In Java, dry conditions generally occur in the northern, southern, and eastern parts of Central Java, most of East Java, and Madura Island. Drought also appears to occur in parts of southern Bali, parts of NTB, and parts of NTT (especially Timor Island and Sumba Island). On the island of Sulawesi, drought is also seen in some parts, especially the Central Sulawesi islands and Southeast Sulawesi.
Several methods, programs, and projects have been launched to tackle the water issue, most of them involving scientific knowledge to be implemented in sectors with high water consumption, including the residential sector, corporate sector, tourism sector, and the agricultural sector. This paper focuses on the conservation programs that encourage water savings through the channels of education, information, and persuasion in the residential sector. By focusing on this area, this paper aims to propose a framework based on theory and previous studies on water scarcity in designing a community engagement program for household water saving. Community involvement is important to develop people's coping mechanisms for the consequences of water scarcity problems. The capability development is essential to support, complement, or even substitute the absence of comprehensive state policies addressing the issue.

Reducing water consumption in rural and urban households can significantly contribute to future natural resource conservation. Initiatives involving the community should be designed appropriately to ensure the gradual change in water consumption behavior. Our inquiry started from a theoretical perspective and systematic review of previous studies before proposing the framework for a community engagement program. We then present the illustration of a program conducted in Tianyar Village, Bali, Indonesia, as a case study, followed by the discussion and conclusion.

\section{Theoretical PERsPectives AND Systematic REVIEW}

\section{A. Underlying Theory}

The importance of involving and empowering communities in water efficiency programs can be viewed from the actor-network theory (ANT). The idea of the network depicts how several parties or actors interact and depend on each other as a network of allies. Latour [4], [5] mention the three key power types in the network: "anybodies" are actors who have little influence or consequence; "somebodies" are actors whom others pay attention to due to their reputation; and "manybodies" are the reputed actors that can be mobilized to support arguments made by individuals [6]. The community can be viewed as the manybodies power type in the network to support a water-saving program. 
In supporting the household water-saving program, people in the community need to be informed, trained, and educated on the various method they can implement to conserve water. The educational program is expected to bring gradual change in water consumption behavior.

The expected change in behavior can be explained by Ajzen's [7] theory of planned behavior (TPB), which explains that the cause of a person's behavior change or a group can be planned because the behavior is not $100 \%$ voluntary and can be controlled. According to TPB, human behavior can be categorized by three kinds of considerations:

1. Behavioral beliefs, which is beliefs about the possible consequences of a behavior

2. Normative beliefs, which is beliefs about the standard expectations of others

3. Control beliefs, which is beliefs of factors that may facilitate or hinder the performance of a behavior

These three considerations need to be in a condition/project/program to change one's behavior. Behavioral beliefs produce good or bad attitudes toward behavior, and normative beliefs produce perceptions of social pressure or subjective norms, whereas control beliefs lead to a perception of control over behavior. Taken together, attitudes toward behavior, subjective norms, and perceptions of behavioral control lead to changes in behavior (behavioral intention). The better a subjective attitude and norm and the greater perception of control, the stronger the intention of a person to perform a behavior.

An approach model to the design of a community-based water conservation program is described in Figure 1.

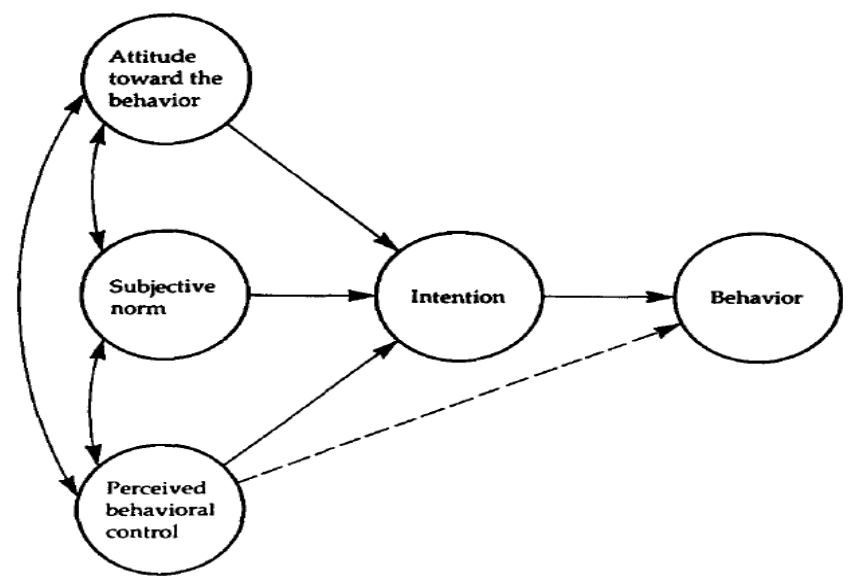

Source: Ajzen [7], page 182

Fig. 1. Theory of Planned Behavior

\section{B. Previous Studies}

Based on previous studies, it can be seen that various factors influence water conservation programs in various areas during different time periods. Although some factors have mixed results, it can be concluded that several significant determinants range from knowledge, attitude, idealistic motives, income level, to women's involvement. A participatory approach is suggested because, since the1970s and1980s, women's involvement in water conservation has been considered crucial to improving the program and project effectiveness due to their considerable roles, concerns, and priorities in water management [8].

\section{PROPOSED FrAMEWORK FOR COMMUNITY ENGAGEMENT PROGRAM}

Based on the theoretical perspectives and findings from previous studies, a framework for designing a community engagement program can now be offered. The framework takes into account the factors or determinants found to be good predictors of a successful water conservation program. Insights from the accounting discipline are also inserted into the framework to construct calculative behavior and to raise awareness of the tangible and intangible costs and benefits of the water-saving program and to create a sense of water accountability in the community.

The proposed framework is depicted in Figure 2.

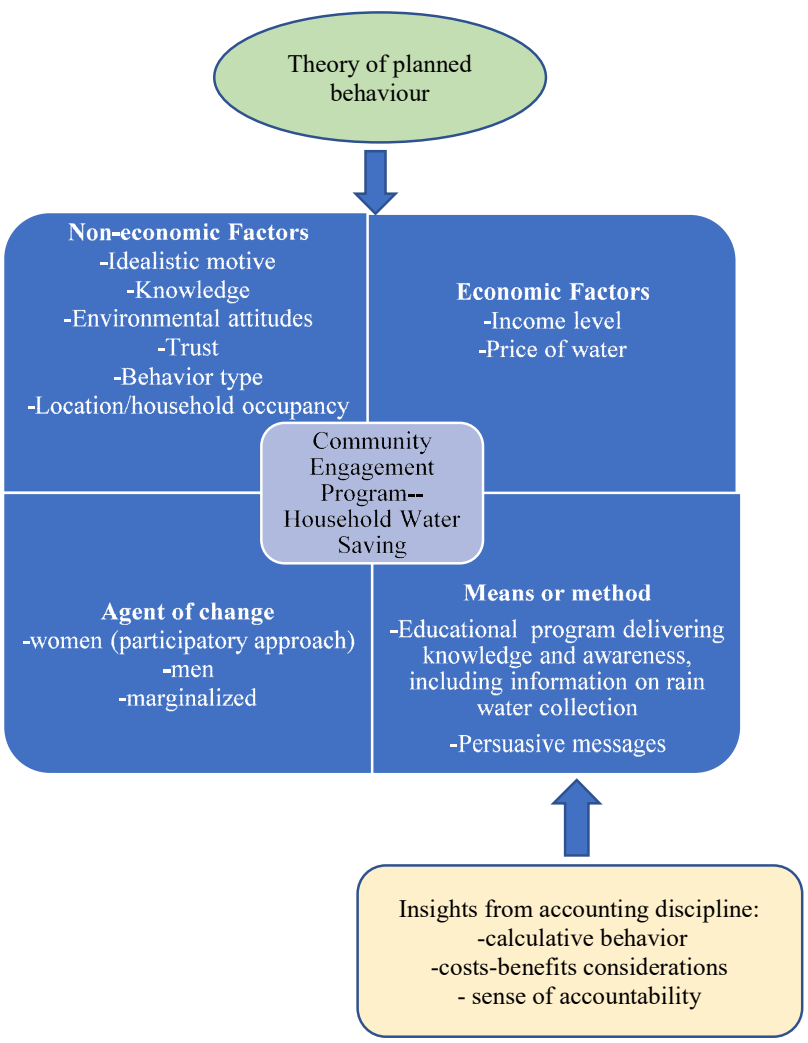

Fig. 2. Proposed Framework for Designing a Community Engagement Program

\section{CASE Study: WATER SCARCITy AND The Design OF COMMUNiTy ENGAGEMENT PROGRAM IN TIANYAR VILLAGE, BALI, INDONESIA}

After proposing the framework, a case study of the community engagement program designed based on said framework is described in this section. The program was conducted recently in Tianyar Village, an area in Bali, Indonesia, experiencing severe drought. The region was selected for its high need for a water conservation program. Also, based on previous studies, location does matter in determining the success of a water conservation program. Communities in regions recently exposed to drought conditions tend to use less water compared to those who have not experienced drought [20]. 


\section{A. Background}

The slogan "Tourism in Bali is Killing People" may be appropriate to illustrate the problem of the water crisis in Bali [9]. The interests of tourists are of great concern and at great expense to the local people. These numbers are more or less similar to those found by the Indonesian Hotels and Restaurants Association in Bali that the use of water by tourists in Bali ranges from 1,300 liters per person per day, depending on the type of hotel or location. Tourists in Kuta use an average of 800 liters per day, Seminyak around 1,400 liters, Jimbaran 2,340 liters, and Ubud 3,270 liters [9]. The highest use in Ubud reflects the charm of this region with its exclusive tourism facilities, including water baths, spas, and swimming pools.

Tourism is the biggest support (80\%) of the economy of Bali and is considered to have contributed to the welfare of society. Tourism activities that do not pay attention to the preservation of the environment and natural resources will bring new problems, however. The abundance of water for tourism in Bali is ironic when compared to the inaccessibility of water by its citizens. This is not only happening in dry areas such as Karangasem but also in the center of tourism in southern Bali. In fact, according to Cole, access to water is a human right, and water should be easy to get, safe, and enough for everyone. The scarcity of clean water in Bali causes various health problems, including cases of diarrhea and skin diseases [10].

This community service program focuses on community empowerment, with the family as the smallest unit [11] in overcoming the problem of water scarcity in Bali. Various activities conducted are the implementation of science and technology for the community, which is expected to go hand in hand with the formal efforts of local governments in managing the water crisis. The proposed program does seem defensive, in the sense that program participants are directed to make water savings, instead of offensive in the form of questioning the existence and role of the tourism industry in Bali. The program is also applied to tourists who come to visit Bali to create synergy with other water main users. Communication with local village government will also be done to create synergy in the form of alignment of direction and movement in handling water crisis problem in Bali, especially in Tianyar Village.

\section{B. Purpose}

The purpose of this community engagement program is to generate public awareness about the current state of the water crisis and develop the skills of the community to address the problem. The program is aimed at creating a water-efficient culture and changing some habits that do not support water-saving efforts. Educational activities are expected to create a mindset to use water wisely to maintain its sustainability, while supporting sustainable tourism activities.

The target of the community program is to effect a change of behavior of water usage appropriately and improve people's quality of life, based on the following parameters:

1. Establishment of agents/motivators who understand the way and importance of water saving (in this case, women/mothers/wives are expected to be the agent of water saving in their family)
2. Transformation of awareness, commitment, willingness, knowledge, skills, and affection given by the Team to the surrounding community

3. The mobilization of local communities to participate in the development of the wider community, namely through the procurement of clean water facilities that will be managed independently after the program is completed

4. Increased public awareness of efforts to improve health through the availability of clean water

6. Increased independence of community groups in maintaining clean water facilities that have been developed

7. Increased income generating efforts for people who are accustomed to buying clean water for household needs through water cost savings

\section{Program Description}

The proposed program, named "Water Counting," is divided into several types of activities for a certain period.

1) Activity 1: Educational Program for at least 50 families in Tianyar Village, Karang Asem Bali.

The main targets are women/mothers/wives who use the most water in the household (for bathing, washing, and cooking) and are expected to become water-efficient agents for other family members to emulate.

Educational programs include:

a. Counting the time it takes to bathe every day. Each family is given a time sheet measured and written daily, with a maximum target of 15 minutes per family member. Families who can achieve this target within two months are given incentives.

b. Whenever possible, each family can be equipped with a timer tool.

c. This activity is done to train everyday water-saving habits, starting from routine bathing activities. Ideally water consumption would be calculated as it is in Australia (monthly water bills completed with water debit information, comparison with the previous month, and savings achieved), but this technology is costly in the absence of adequate funds from donor or sponsors. The easiest way therefore is to use the timing method, assuming that the less time spent, the less water is wasted.

d. In addition to water-saving bathing habits, each family is also equipped with several other ways to save water in the household, namely:

1. Monitoring the use of water in the activities of washing dishes, vegetables, and fruits and soaking frozen food using a container such as a wash bowl or dishwasher; eliminating this last activity can save 40 liters of water. Washing using a basin only requires about 10 liters of water while washing under an open tap for five minutes uses 50 liters of water.

2. Washing clothes using water-saving materials, distributed for free to participants, such as a product that from the Once-Rinse Movement

3. Turning off the tap while brushing your teeth because this can save at least 40 liters of water 
4. Turning off the shower when using soap

5. For Moslem participants: performing ablution by not scattering water (the example of how to perform ablution according to the Sunnah of the Prophet is demonstrated to participants)

6. Collecting rainwater after the first day of the rainy season (to avoid pollution or pollution from the atmosphere) in a closed container that can be used to water the plants in the garden, yard, or front porch of the house

All these activities are written on a checklist as a reminder for each family member. Each family is encouraged to make as much effort as possible and fill out the checklist. At the end of each month, the activities will be evaluated by communication through Whatsapp with the participants. The target for changing behavior is after four months of the educational program.

All of these activities are targeted to construct the calculative behavior in water consumption. Prior to providing the list of activities, participants receive persuasive information on water scarcity problem and the importance, including in terms of the costs and benefits, of saving water in daily use. The activities of measuring water use and filling in the checklist are expected to create the sense of accountability among participants.

2) Activity 2: Building the clean water facilities to be managed by the community after the program ends

3) Activity 3: Water saving campaign to tourists

a) The distribution of stickers and leaflets in English and Indonesian about the water crisis and the importance of water-saving habits to domestic and foreign tourists in Bali, primarily to locations with high water consumption: Kuta (average 800 liters per day), Seminyak (1,400 liters), Jimbaran (2,340 liters), and Ubud (3,270 liters)

b) Because tourists do not stay long, it is difficult to complete the educational program outlined as Activity 1. The distribution of stickers and leaflets is expected however to build awareness and empathy about the water crisis problem in Bali.

c) The distribution of stickers and leaflets is also performed by contacting local hotels as well as communication with the Indonesian Hotel and Restaurant Association in Bali for possible discussion activities on water and sustainable tourism as another means of information dissemination.

\section{Community Involvement and Sustainability}

Communities will be involved in this program if they see the benefits of joining the water-saving program for water sustainability and overall improved quality of life. Cooperation with non-profit organizations should be maintained for developing the clean water facilities that will then be handed over to communities to manage independently. Indicators that ensure the success of the program are the creation of water-efficient behavior, at least in the community of program participants, and the maintenance of clean water facilities by the community groups.

\section{E. Process Diagram}

Figure 3 depicts the process diagram of the community engagement program. The indicators used to measure outcomes are:

1. The achievement of a maximum of 15 minutes for bathing activities, which is part of the formation of water saving habits in a family

2. The implementation of at least four water-saving activities on the checklist

3. The distribution of stickers and leaflets to a minimum of 20 tourists at each point of distribution

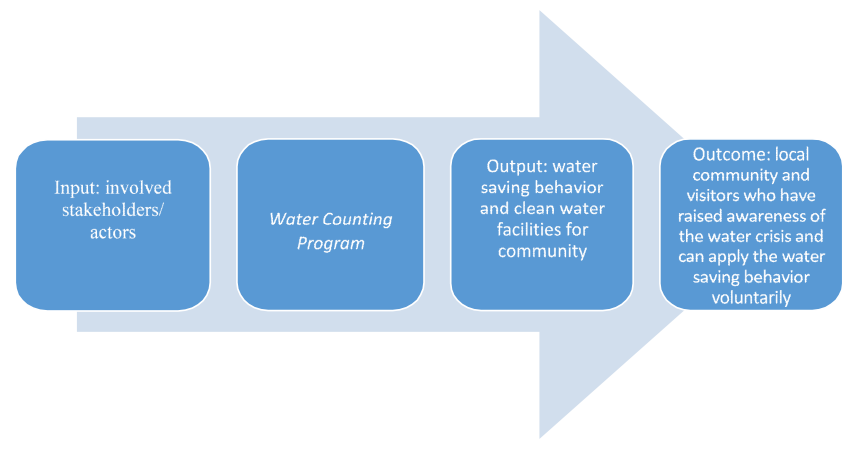

Fig. 3. The Diagram Process of the Community Engagement Program

\section{CONCLUSION}

This paper has presented a systematic review of theoretical perspectives and previous studies on a water conservation program to inform the design of a community engagement project. The approach taken delivers the message of the importance of knowledge and wisdom from theory and previous research in designing an appropriate and successful community engagement program. The framework resulted from the systematic review of a project of water conservation in Tianyar Village, Bali, Indonesia. The case study is expected to serve as an example of the embodiment of the developed framework, which can be developed further for future research or a community engagement program.

This paper is limited to designing framework for a community engagement program of daily household water consumption. Future research can explore water savings in other areas such as in farming activities and agriculture. This paper also focuses on the demand side of water and hence proposes a framework to enhance the capabilities of local communities in managing their demand or consumption of water. Future research can also focus on enhancing the communities' capabilities in generating the clean water supply.

\section{ACKNOWLEDGMENT}

This paper is based on the community engagement program on "Water Accounting in Tianyar Village, Bali", funded by Universitas Indonesia in 2018.

\section{REFERENCES}

[1] Mekonnen, M. M., \& Hoekstra, A. Y. (2016). Four billion people facing severe water scarcity. Science advances, 2(2), e1500323.

[2] World Economic Forum, Global Risks 2015, 10th Edition (World Economic Forum, Geneva, Switzerland, 2015). 
[3] Vörösmarty, C. J., Green, P., Salisbury, J., \& Lammers, R. B. (2000). Global water resources: vulnerability from climate change and population growth. Science, 289(5477), 284-288.

[4] Latour, B. (1987), Science in Action: How to Follow Scientists and Engineers through Society, Harvard University Press, Cambridge, MA.

[5] Latour, B. (2005), Reassembling the Social. An Introduction to Actor Network Theory, Oxford University Press, Oxford.

[6] Egan, M. (2014). Making water count: water accountability changes within an Australian university. Accounting, Auditing \& Accountability Journal, 27(2), 259-282.

[7] Ajzen, I. (1991). The theory of planned behavior. Organizational behavior and human decision processes, 50(2), 179-211.
[8] Ivens, S. (2008). Does increased water access empower women? Development, 51(1), 63-67.

[9] Muhajir, A. (2015). Pariwisata lahirkan ancaman krisis air di Bali. Diakses dari https://www.rappler.com/world/regions/asia-pacific/ indonesia/90735-pariwisata-ancam-krisis-air-bali

[10] Juniarta, I. (2017). Bali's Water Question. Diakses dari http://www.thejakartapost.com/life/2017/04/13/balis-waterquestion.html.

[11] Sultana, F. (2018). Gender and Water in a Changing Climate: Challenges and Opportunities. In Water Security Across the Gender Divide (pp. 17-33). Springer, Cham. 